\title{
Special issue in honor of Friedrich Kremer
}

\author{
Andreas Schönhals • Christine M. Papadakis
}

Published online: 20 June 2014

(C) Springer-Verlag Berlin Heidelberg 2014

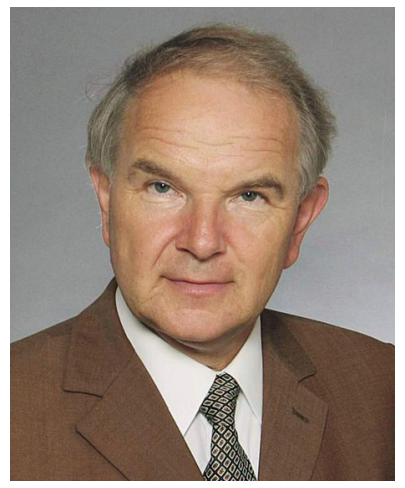

Prof. Dr. Friedrich Kremer is celebrating his 65 th birthday this year. Furthermore, also for this reason, he resigned from the position as an Editor-in-Chief of the journal Colloid and Polymer Science [1]. In his more than 20 years of successful editorship, he has substantially contributed to develop Colloid and Polymer Science to become a leading international journal in the field of polymers and colloids including their manifold connections with other branches of science. He will remain in a close connection to the journal as the new Chief Advisory Editor. To appreciate both his 65th birthday and his prosperous engagement for this journal, Springer is pleased to launch the present special issue of Colloid and Polymer Science dedicated to Prof. Dr. Friedrich Kremer. Friends,

A. Schönhals $(\square)$

BAM Bundesanstalt für Materialforschung und - prüfung, Unter den Eichen 87, 12205 Berlin, Germany

e-mail: andreas.schoenhals@bam.de

\section{M. Papadakis}

Physik-Department, Fachgebiet Physik weicher Materie, Technische

Universität München, James-Franck-Str. 1, 85748 Garching,

Germany

e-mail: papadakis@tum.de

editors, and colleagues, as well as coworkers and former students contribute to this special issue with their own selected original scientific work in order to honor Friedrich (or in short form: Frieder) not only as a leading scientist but also as a person with an outstanding personality.

Some biographical details, his most important fields of scientific research, and important milestones of the scientific career of Friedrich are nicely described in Prof. Dr. Graham Williams' Laudatio (DOI 10.1007/s00396-014-3239-3). Based on his deep understanding of physics and physical chemistry, Frieder always tried to develop well-suited, adapted experiments to answer open topical questions in the fields of glass-forming materials, liquid crystals, polymers, or colloids, to mention only but a few. In many cases, these experiments have been designed at the edge of what was/is experimentally feasible at the given time. This regards for instance, and in particular, the development of Broadband Dielectric Spectroscopy in a form which could later even be commercialized, the adaptation of the technique of optical tweezers to measure small forces between colloids and/or macromolecules, as well as the implementation of nanostructured electrodes to access the dielectric behavior of semiisolated polymers at surfaces. Also, this list of Frieder's achievements can only give a very rough impression and never be exhaustive.

It was the special way how Friedrich has been carrying out his research, which has been at the origin of his great scientific successes. His approach consists of a combination of different aspects:

(a) The identification of hot topics in the field which are worth to be studied in greater detail.

(b) His studies have always been based on his in-depth physical knowledge, combined with the consequent development and pursuit of strategies to investigate the selected topic-sometimes even by employing 
unconventional approaches. The latter point also includes, on the one hand, motivating or rather enthusing coworkers like $\mathrm{PhD}$ students and calling for an engaged work, but also, on the other hand, his ability to accept diverging opinions when they are proven by solid arguments.

(c) He has always known to spread the obtained results in the community and to bring it to their attention in brilliant talks and lectures at conferences and meetings, as well as by rapidly publishing in highly ranked journals.

However, this is only one aspect of Frieder's impact onto the scientific community. Another point concerns first of all the education of young academics. Besides his duties as a full university professor to give lectures in physics, he has been an advisor for many Master and Diploma theses. Until now, he has initiated and successfully supervised $40 \mathrm{PhD}$ theses. The scientific results obtained during these theses provide not only the sound experimental and theoretical basis for many of the highly cited papers which he has published together with his coworkers. Moreover, many of his alumni today hold highranked positions both in academia and in the industry. Finally, he was the mentor of three habilitation theses. Two of the successful degree holders are now holding professor positions at well-recognized universities (among them, for example, one of us guest editors of this special issue).

Frieder's impact on the international scientific landscape has been and is even more multifaceted, far beyond these mentioned activities. Since his time at the Max-PlanckInstitute for Polymer Research in Mainz, he has always strived to invite guest researchers from many countries all over the world to stay in his laboratories for shorter or longer periods of time. On the one hand, he has supported these guest scientists by inviting them to participate in the lively research work in a stimulating environment but always giving them the opportunity to develop their own scientific ideas. For many researchers, this has opened the door to the scientific community. On the other hand, in this way, he indirectly helped to build up a strong international scientific network across Europe and beyond. For the same reason, he has acted as chairman of the branch "Chemical Physics Polymer Physics" of the German Physical Society for several years and also as a chairman of the International Dielectric Society. It fits into the line of these activities that Friedrich (co)organized several international conferences like the conference for Polymers and Advanced Technologies (PAT 1997), two meetings of the International Dielectric Society $(2002,2012)$, and two NATO Advanced Research Workshops related to Broadband Dielectric Spectroscopy $(2007,2011)$.

Last, but not the least, the guest editors would like to thank all contributors to this special issue of Colloid and Polymer Science for their constructive and fruitful cooperation. It is only with their help and the quality of their selected research work that this special issue can have such an outstanding quality, appreciating and celebrating both Frieder's scientific achievements and his more that than 20 years of engagement for Colloid and Polymer Science.

Normally, at the age of 65 , people retire and more or less stop their active daily work. Everybody, who knows Frieder, will probably realize that it is very unlikely to apply for him...

For this "new" period in your personal and scientific life, dear Frieder, we and all the contributors would like to wish you the necessary health, the physical strength, and many, many more of your splendid ideas.

Happy birthday, Frieder!

Summer 2014, Berlin, and Garching

Andreas Schönhals, and Christine M. Papadakis

\section{Reference}

1. Wassermann TN, Richtering W (2014) Colloid Polym Sci 292:1-3 